\title{
(6) OPEN ACCESS \\ Building a taxonomy of integrated palliative care initiatives: results from a focus group
}

\author{
Benjamin Ewert, ${ }^{1}$ Farina Hodiamont, ${ }^{1}$ Jeroen van Wijngaarden, ${ }^{2}$ \\ Sheila Payne, ${ }^{3}$ Marieke Groot, ${ }^{4}$ Jeroen Hasselaar, ${ }^{4}$ Johann Menten, ${ }^{5}$ \\ Lukas Radbruch ${ }^{1}$
}

${ }^{1}$ Klinik für Palliativmedizin, Universitätsklinikum Bonn, Bonn, Germany

${ }^{2}$ Department of Health Service and Management of Organizations, Erasmus University Rotterdam, Rotterdam, The Netherlands

${ }^{3}$ International Observatory on End of Life Care, Lancaster University, Lancaster, UK ${ }^{4}$ Department of Anaesthesiology, Pain and Palliative Care, Radboud University Medical Center, Nijmegen, The Netherlands

${ }^{5}$ Radiation Oncology Department, University Hospital Leuven, Leuven, Belgium

\section{Correspondence to}

Dr Benjamin Ewert, Klinik für Palliativmedizin, Universitätsklinikum Bonn, Sigmund-Freud-Str. 25 Bonn 53127, Germany; benjamin.ewert@ukb.uni-bonn. de

Received 5 January 2015 Revised 23 July 2015 Accepted 7 October 2015

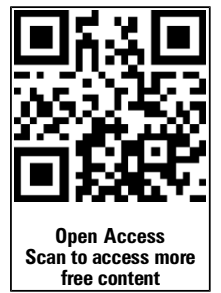

CrossMark

To cite: Ewert $B$

Hodiamont $F$, van

Wijngaarden J, et al. BMJ

Supportive \& Palliative Care

2016:6:14-20.

\section{ABSTRACT}

Background Empirical evidence suggests that integrated palliative care (IPC) increases the quality of care for palliative patients and supports professional caregivers. Existing IPC initiatives in Europe vary in their design and are hardly comparable. InSuP-C, a European Union research project, aimed to build a taxonomy of IPC initiatives applicable across diseases, healthcare sectors and systems.

Methods The taxonomy of IPC initiatives was developed in cooperation with an international and multidisciplinary focus group of 18 experts. Subsequently, a consensus meeting of 10 experts revised a preliminary taxonomy and adopted the final classification system.

Results Consisting of eight categories, with two to four items each, the taxonomy covers the process and structure of IPC initiatives. If two items in at least one category apply to an initiative, a minimum level of integration is assumed to have been reached. Categories range from the type of initiative (items: pathway, model or guideline) to patients' key contact (items: nonpc specialist, pc specialist, general practitioner). Experts recommended the inclusion of two new categories: level of care (items: primary, secondary or tertiary) indicating at which stage palliative care is integrated and primary focus of intervention describing IPC givers' different roles (items: treating function, advising/consulting or training) in the care process.

Conclusions Empirical studies are required to investigate how the taxonomy is used in practice and whether it covers the reality of patients in need of palliative care. The InSuP-C project will test this taxonomy empirically in selected initiatives using IPC.

\section{BACKGROUND}

Integrated care has become one of the key concepts in healthcare policy and practice. ${ }^{1-3}$ It is a means to optimise system performance and healthcare outcomes. Particularly with regard to palliative care, 'the time has come" ${ }^{4}$ for a more integrated service provision. Professional caregivers agree that palliative care (PC) has many positive effects such as improved symptom control, ${ }^{5}$ less caregiver burden, improvement in continuity of care and coordination of care. ${ }^{6}$ As recently stated in a World Health Assembly (WHA) resolution, what is needed is 'strengthening of palliative care as a component of integrated treatment throughout the life course'. ${ }^{7}$ Hence, the integration of PC in healthcare schemes, such as those for cancer and chronic diseases, has become a major challenge of healthcare provision. ${ }^{1}$ However, at least in Europe, there are few models of integrated palliative care (IPC) such as the Liverpool Care Pathway (LCP) on end-of-life care that have been developed and implemented yet. Despite an existing overview on end-of-life pathways, ${ }^{8}$ there is a lack of comprehensive knowledge on which factors are constitutive for IPC and how to compare existing IPC initiatives systematically.

Since 'integrated care as a concept is an imprecise hodgepodge, ${ }^{9}$ it is a crucial task 'to somehow develop broad consensus around a common terminology and typology (or taxonomy)'. ${ }^{9}$ InSuP-C, ${ }^{i}$ an international research project on IPC in Europe, seeks to close this research gap. ${ }^{10}$ In particular, the study aims to

iThe acronym stands for 'patient centred integrated palliative care pathways in advanced cancer and chronic disease'. The project runs from 2012 to 2016 and is funded by the 7th framework programme of the EU-Commission. 
find out the best way to deliver care to people who have advanced cancer, heart failure or lung disease as they come towards the end of their lives. ${ }^{10}$ With regard to IPC, InSuP-C uses the following working definition:

Integrated palliative care involves bringing together administrative, organisational, clinical and service aspects in order to realise continuity of care between all actors involved in the care network of patients receiving palliative care. It aims to achieve quality of life and a well-supported dying process for the patient and the family in collaboration with all the caregivers (paid and unpaid). ${ }^{11}$

In order to analyse the provision of IPC, InSuP-C sets out to develop a taxonomy of IPC initiatives that is applicable across selected diseases, healthcare sectors and systems in Europe. The taxonomy needs to encompass the process of IPC including structure, interaction and time of integration in order to compare IPC initiatives across Europe and to identify best practices. The taxonomy was revised and finalised in a consensus meeting with an international focus group. This paper describes the results from the focus group and the final taxonomy.

\section{METHODS}

The preliminary taxonomy emerged from an inventory of existing IPC initiatives based on a preliminary analysis of 34 expert interviews and an online survey among members of the European Association for Palliative Care (EAPC) mailing list. The details and results of these studies will be published elsewhere. For this study, the consortium of InSuP-C recruited a multidisciplinary panel of experts in order to monitor and contribute to the development of the taxonomy. Each of the six country teams was requested to suggest 2-4 national champions of IPC by applying a snowball system. For instance, two of three Belgium experts were suggested by the Flemish Palliative Care Federation. The final panel consisted of 18 experts, all of them EAPC members, 4 from the UK, 3 from Belgium, 3 from Germany, 2 from Hungary, 3 from the Netherlands and 3 from Spain. Experts had different professional backgrounds: 10 physicians (ie, general practitioners (GPs), oncologists, PC specialists and pulmonologists), 3 healthcare researchers, 1 psychologist, 1 social worker, 1 mental health counsellor, 1 user representative and 1 nurse. All panel members were asked to critically examine the preliminary taxonomy (figure 1).

In concrete terms, experts were asked 'Do you think the preliminary taxonomy is useful to classify IPC initiatives?' and 'Which revisions are necessary to apply the classification system across Europe?'. Experts were also asked to determine suitable indicators for benchmarking. Their input, provided in written form via email, was used to revise the preliminary taxonomy. To finalise the taxonomy, a consensus meeting was held in September 2014 in Bonn. The meeting was attended by 10 of the 18 selected experts, ii including 4 physicians, 2 healthcare researchers as well as four experts from psychology, nursing, social work and mental health counselling. All of the 18 experts were provided with an electronic version of the revised taxonomy four weeks before the meeting. Expert feedback before the consensus meeting, counterbalancing also the absence of eight experts during the meeting itself, resulted in a number of additional recommendations (see Developing a taxonomy of IPC initiatives in Europe section), though there was a general acceptance of the main characteristics of the preliminary taxonomy. The meeting was organised around three key questions:

- How can we conceptualise IPC?

- What is the added value of a taxonomy?

- What taxonomy for IPC can be developed that is applicable across diseases, healthcare sectors and systems?

Answers emerged by applying a mixed set of methodologies such as brainstorming, use of index cards and pinboards and guided expert inputs. Experts' oral and written (prior to the consensus meeting) contributions were equally taken into account. Thus, care was taken that single opinion leaders did not dominate the consensus process. The taxonomy was revised category by category until consensus was achieved. Hence, decisions on categories and terms used represent the lowest common denominator instead of majority decision-making. If experts agreed to disagree, no decision was taken. Finally, all participants of the consensus meeting unanimously agreed to a revised version of the taxonomy of IPC initiatives in Europe.

\section{RESULTS}

The consensus meeting ${ }^{\mathrm{iii}}$ was focused on the three key questions: the conceptualisation of IPC, the added value of a taxonomy and the development of the taxonomy.

\section{Conceptualisation of IPC}

Finding consent on a complex approach such as IPC requires a mutual understanding of underlying key concepts. Therefore, the meeting started by discussing IPC in healthcare provision. Almost all experts confirmed that a continuous process of care without gaps is of utmost importance. Integration has to be defined from the perspective of the patient and is reached when patients receive PC tailored to their needs. This rather vague position was challenged by the working

\footnotetext{
${ }^{i i}$ Eight experts were not able to attend the meeting due to several reasons such as illness, vacation and conflicting schedules.

iii Expert quotes emerging from the consensus meeting are highlighted by inverted commas.
} 


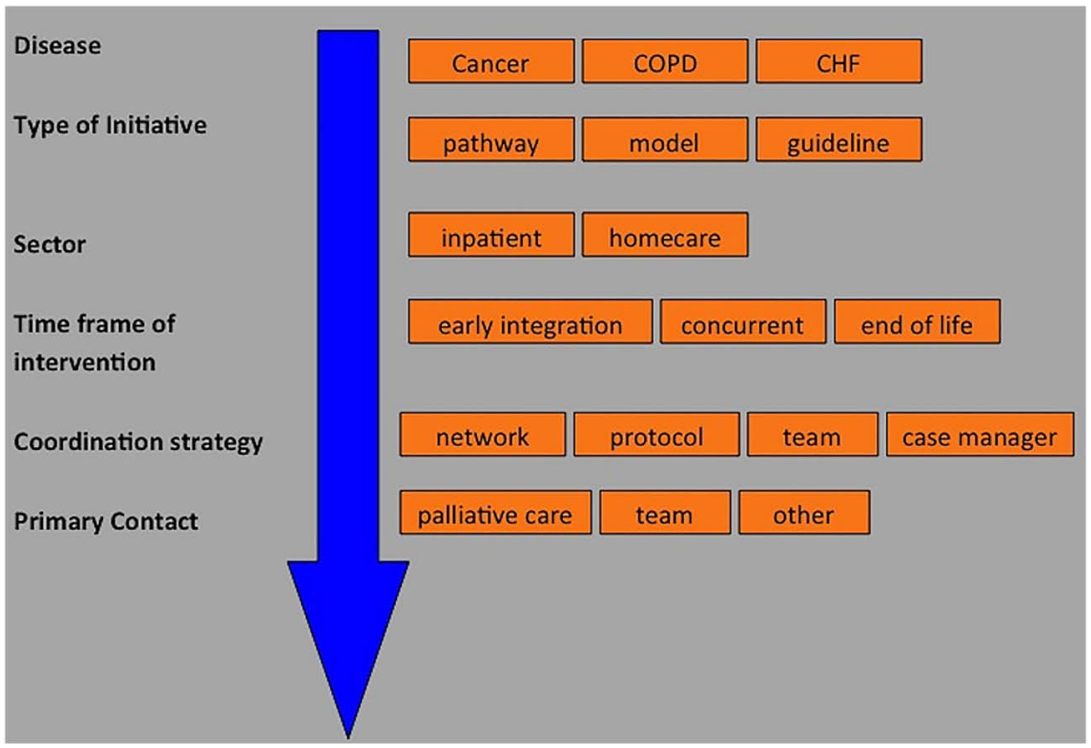

Figure 1 Preliminary taxonomy of integrated palliative care initiatives in Europe (CHF, chronic heart failure; COPD, chronic obstructive pulmonary disease).

definition of IPC (see Background section) in the InSup-C project. Confronted with this operationalisation of IPC, additional or deviating requirements were discussed by the experts. First of all, there was a rather normative turn by insisting that IPC should be delivered to all patients 'in need of palliative care' instead of patients 'receiving palliative care'. Experts tried to specify when patients should be enrolled in PC provision. For instance, experts recommended adding the term 'early integration' to the definition and capturing the 'longitudinal and service orientation of IPC'. A strong emphasis on the continuity of care would differentiate IPC from PC provided by single physicians at the end of patients' lives. Instead, IPC 'focuses on a network and collaboration among multidisciplinary professionals'. Hence, experts did not agree on a new definition of IPC but discussed the aforementioned aspects and potential amendments that are crucial from their point of view. Therefore, during the progress of the meeting, the working definition, introduced in the background part of this paper, was used to develop the taxonomy.

\section{Added value of a taxonomy}

Among the experts, the question emerged initially whether developing a taxonomy of IPC initiatives is necessary and worthwhile. After all, as one expert stated, 'building a taxonomy may go against the pioneering spirit of palliative care activists'-an attitude that is frequently adopted by practitioners voicing doubts about standardised assessment of their work performance. However, there was consensus among the experts that the target users of a taxonomy are typically not professional caregivers, but researchers and policymakers in the first place. In short: a taxonomy may facilitate the navigation through and the comparison of IPC initiatives in different healthcare systems. It does not facilitate the provision of palliative care. Expert statements ranging from 'a taxonomy helps to structure our thinking' to 'it gives an overview about different palliative care approaches' support this overall assessment. In addition, a classification system 'may inform about the pitfalls of integrated care' and helps to improve existing IPC initiatives. However, the main purpose of a taxonomy may be its positive effects for the reputation and the standing of PC as a discipline within healthcare systems. According to experts, 'a taxonomy may stop tedious discussions on what IPC is all about', and 'it may also help people to differentiate between palliative care and palliative medicine'. Classifying IPC models further contributes to its establishment within healthcare systems. Last but not least, 'a taxonomy may contribute to future research and education' provided it consists of both strong definitions to delineate IPC from non-IPC services and sufficient elasticity ${ }^{12}$ in order to be applicable to different healthcare contexts. Such an orientation towards applicability especially makes the building of a taxonomy crucial. Presently, the landscape of IPC models in Europe is 'highly fragmented and lacks equity in terms of access'. As reported, the IPC provision in Hungary, for instance, is still in its infancy, while, however, ten different models exist in the Netherlands.

\section{Developing a taxonomy of IPC initiatives in Europe}

The preliminary taxonomy that was presented to all 18 experts included six consecutive categories: disease, type of initiative, sector, time frame of intervention, coordination strategy and primary contact. Each category consists of two to four items. For instance, the category disease was limited to cancer, 


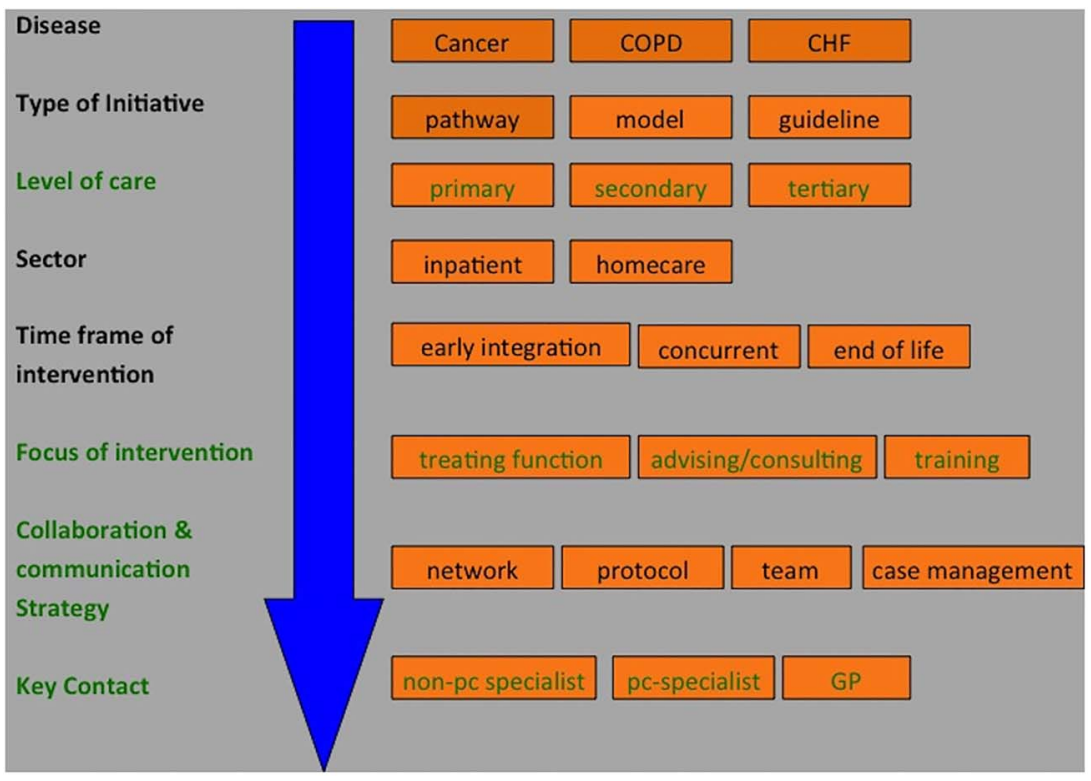

Figure 2 Revised taxonomy of integrated palliative care initiatives in Europe (changes are highlighted in green; $\mathrm{CHF}$, chronic heart failure; COPD, chronic obstructive pulmonary disease; GP, general practitioner; PC, palliative care).

chronic obstructive pulmonary disease and chronic heart failure since these illnesses make up the scope of InSuP-C, ${ }^{\text {iv }}$ whereas the category time frame of intervention consists of the items early integration, concurrent and end of life (see figure 1). A minimum of IPC is provided if all categories can be applied and if in at least one of these categories ${ }^{\mathrm{v}}$ more than one item can be ticked. Feedback from the experts prior to the consensus meeting focused on two categories that raised concerns: sector and primary contact.

In the preliminary taxonomy, the category sector consisted of the items inpatient and homecare. However, most experts argued that this suggested a dualism that does not cover the diversity of IPC initiatives in practice. An additional third sector transmural care was proposed where IPC starts in an institutionbased setting, that is, in-hospitals, hospices or outpatient clinics, but is continued outside these institutions, for example, in the home of patients. Most experts also commented on the category primary contact, because the preliminary taxonomy did not include a separate item for GPs, but subsuming their work under the item other. In their view, GPs play a vital role since they often initiate and coordinate the provision of IPC.

Taking these concerns into account but without making final changes yet, the preliminary taxonomy was submitted for revision at the consensus meeting. Deriving from previous exchange and discussion on the nature of IPC and the overall necessity of a classification system, the revision of the preliminary

\footnotetext{
${ }^{\text {iv }}$ In practice and outside the InSuP-C project, an expansion of the taxonomy of other diseases such as neurodegenerative conditions might be necessary.

${ }^{v}$ This rule does not hold true for the category disease.
}

taxonomy marked the final part of the consensus meeting. At this stage, experts were explicitly asked to refine categories and items in the taxonomy before the final version was to be adopted.

As it turned out, the main challenge was to agree on a taxonomy encompassing the process of IPC as well as the structure. The experts expanded the revised taxonomy (figure 2) with two new categories: The category level of care including the items primary, secondary and tertiary indicates at which stage of specialisation and expertise PC is integrated. Experts agreed not to include informal caregivers in the taxonomy, despite the immense importance of family members, friends and volunteers in practice, ${ }^{13}$ since they are not a regular feature of IPC initiatives but a potential source of additional support in all stages of disease and all treatment settings. Second, the category primary focus of intervention including the items treating, advising/consulting and education/training classifies specialist palliative caregivers' role in IPC. Two existing categories were renamed: The category coordination strategy was changed into collaboration and communication strategy because the emphasis of the category is on the interaction between professional caregivers rather than merely on organisational issues. The category primary contact was changed into key contact. This category had included the items palliative care, team and other, which were changed into non-pc specialists, pc specialists and GPs. Hence, the latter are recognised as key persons in the coordination of IPC provision.

To summarise, items of the revised taxonomy have been defined as follows (table 1).

Participants of the consensus meeting also discussed the category sector and its items inpatient and homecare with the intention of clarifying the meaning of 
Table 1 Definitions of items used in the revised taxonomy

\begin{tabular}{|c|c|c|c|c|}
\hline Category & Item 1 & Item 2 & Item 3 & Item4 \\
\hline Type of initiative & $\begin{array}{l}\text { Guideline: Guidelines are } \\
\text { systematically developed } \\
\text { statements to assist practitioners } \\
\text { and patient decisions about } \\
\text { appropriate healthcare for } \\
\text { specific clinical circumstances }\end{array}$ & $\begin{array}{l}\text { Pathway: A care pathway is a } \\
\text { complex intervention for the } \\
\text { mutual decision-making and } \\
\text { organisation of care processes } \\
\text { for a well-defined group of } \\
\text { patients during a well-defined } \\
\text { period. A pathway may use } \\
\text { guidelines to provide clinical care }\end{array}$ & $\begin{array}{l}\text { Model: Description of a 'model' } \\
\text { or 'pilot' project of integrated } \\
\text { palliative care (IPC) in a } \\
\text { defined setting (eg, hospital, } \\
\text { nursing home, home, palliative } \\
\text { care (PC) team) }\end{array}$ & - \\
\hline Level of care & $\begin{array}{l}\text { Primary: General practitioner } \\
\text { (GP), nursing service, community } \\
\text { care }\end{array}$ & $\begin{array}{l}\text { Secondary: Specialist physicians, } \\
\text { specialist nursing services, } \\
\text { hospitals, inpatient hospices }\end{array}$ & $\begin{array}{l}\text { Tertiary: Academic training } \\
\text { centres, comprehensive cancer } \\
\text { centres }\end{array}$ & - \\
\hline Sector & $\begin{array}{l}\text { Inpatient/institution centred: PC } \\
\text { for patients is focused on an } \\
\text { institution-based setting, ie, } \\
\text { in-hospitals, hospices or } \\
\text { outpatient clinics, and is not } \\
\text { continued outside these } \\
\text { institutions (even when the } \\
\text { condition of the patient } \\
\text { deteriorates) }\end{array}$ & $\begin{array}{l}\text { Homecare: PC provided at the } \\
\text { place where patients } \\
\text { permanently live, that is, in their } \\
\text { homes, residential homes or } \\
\text { nursing homes }\end{array}$ & - & - \\
\hline $\begin{array}{l}\text { Time frame of } \\
\text { intervention }\end{array}$ & $\begin{array}{l}\text { Early integration: PC needs are } \\
\text { identified at an early stage/PC } \\
\text { starts from the time of diagnosis }\end{array}$ & $\begin{array}{l}\text { Concurrent: PC becomes } \\
\text { integrated in the course of } \\
\text { advanced disease and lasts till } \\
\text { the patient's death }\end{array}$ & $\begin{array}{l}\text { End of life: PC sets in the final } \\
\text { stage of the disease }\end{array}$ & - \\
\hline $\begin{array}{l}\text { Focus of } \\
\text { intervention }\end{array}$ & $\begin{array}{l}\text { Treating function: PC specialists' } \\
\text { main focus is directed at the } \\
\text { treatment of patients }\end{array}$ & $\begin{array}{l}\text { Advising/consulting: PC } \\
\text { specialists' main focus is directed } \\
\text { at the consultation of patients } \\
\text { and their relatives (family } \\
\text { caregivers) }\end{array}$ & $\begin{array}{l}\text { Training: PC specialists' main } \\
\text { focus is directed at the } \\
\text { education of professionals and } \\
\text { family caregivers involved in the } \\
\text { IPC process }\end{array}$ & - \\
\hline $\begin{array}{l}\text { Collaboration and } \\
\text { communication } \\
\text { strategy }\end{array}$ & $\begin{array}{l}\text { Network: There is a network of } \\
\text { PC expertise available, that } \\
\text { knows each other well and is } \\
\text { easily accessible for PC caregivers } \\
\text { and any other health-related } \\
\text { profession }\end{array}$ & $\begin{array}{l}\text { Protocol: Standardised referrals } \\
\text { and treatments plans are in } \\
\text { place to coordinate care }\end{array}$ & $\begin{array}{l}\text { Team: Caregivers are part of a } \\
\text { single team (for specific } \\
\text { patients) focusing on a single } \\
\text { treatment plan with regular } \\
\text { meetings. This team may be } \\
\text { hospital based or community } \\
\text { based }\end{array}$ & $\begin{array}{l}\text { Case management: A case } \\
\text { manager is primarily } \\
\text { responsible for involving all } \\
\text { relevant caregivers and } \\
\text { coordination of care for } \\
\text { specific patients. Case } \\
\text { management can also be } \\
\text { hospital based or community } \\
\text { based }\end{array}$ \\
\hline Key contact & $\begin{array}{l}\text { Non-pc specialist: The treatment } \\
\text { of patients is coordinated by } \\
\text { professionals without a } \\
\text { specialisation in PC (excluding } \\
\text { GPs) }\end{array}$ & $\begin{array}{l}\text { Pc-specialist: The treatment of } \\
\text { patients is coordinated by } \\
\text { professionals with a } \\
\text { specialisation in PC (eg, a nurse } \\
\text { specialised in PC; excluding GPS) }\end{array}$ & $\begin{array}{l}\text { GPs: The treatment of patients } \\
\text { is coordinated by GPs } \\
\text { (including those with } \\
\text { specialisation in palliative care) }\end{array}$ & - \\
\hline
\end{tabular}

the category's two items: on the one hand, an institution-based provision of care and, on the other hand, community-based provision of care represent the key difference among institutional and ambulatory care in most European healthcare systems. However, no consensus was reached on a revised terminology for this category. Likewise, the introduction of transmural care as a third sector, ${ }^{\mathrm{vi}}$ suggested by experts within the pretest phase, was not confirmed in the meeting due to a lack of consensus.

The consented taxonomy allows us to classify any ICP initiative in Europe. Figure 3 shows the taxonomy

\footnotetext{
${ }^{\mathrm{vi}}$ Moreover, outpatient and hospice care were discussed as potential additional sectors. Though, since both terms have very different meanings across healthcare systems no consensus was reached to include them in the taxonomy.
}

applied on a specialised homecare PC initiative in Germany.

Blue arrows highlight possible trajectories of a specialised homecare PC initiative in Germany that are not mutually exclusive, for example, PC may have different foci of intervention such as training function or advising/consulting.

\section{DISCUSSION}

Developing a taxonomy of IPC initiatives has been a key task of the InSuP-C project. The participation of an international and multidisciplinary focus group proved to be a valuable source avoiding pitfalls and a narrow-minded attitude during the drafting of the taxonomy. Experts assured the quality of the final taxonomy of IPC initiatives in three respects: First, they ensured a broad application of the classification 


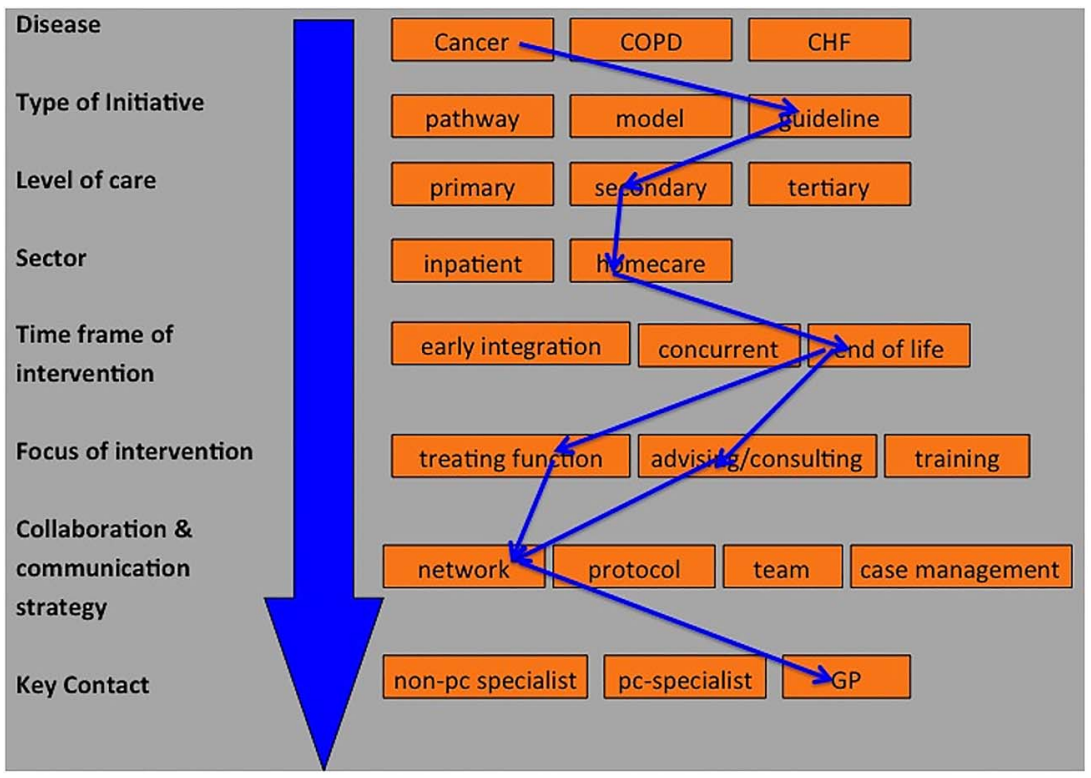

Figure 3 Taxonomy applied on a specialised homecare palliative care initiative in Germany (blue arrows; CHF, chronic heart failure; COPD, chronic obstructive pulmonary disease; GP, general practitioner; PC, palliative care).

system to be built up by contributing perspectives going beyond the scope of the InSuP-C project. For instance, experts introduced the category primary focus of intervention enhancing options to classify IPC providers' work. Second, they sought to balance the taxonomy between flexibility and robustness. While flexibility is necessary to compare IPC to other healthcare services, robustness is needed to define the nature of IPC and, in consequence, help to delineate it from adjacent disciplines (eg, long-term care). Third, experts advised including GPs as a single item belonging to the category key contact. This is in line with a toolkit recently developed by an EAPC task force aiming to promote 'palliative care in the community'. ${ }^{14}$

Moreover, our findings demonstrate how difficult it is to agree on a broad consensus on what integrated care means in relation to PC and which conditions are indispensable for its realisation. This general dilemma, according to which multiple dimensions of integrated care are difficult to fit in a 'simple' taxonomy including a limited number of categories (see figure 1), has been partly solved by developing a multilayered taxonomy (see figure 2). Nevertheless, the consented tool remains suboptimal as it had to balance high discriminatory power with broad applicability due to huge differences between European healthcare systems. For instance, in the UK hospice care, a potential item of the category sector can be provided both in an inpatient and outpatient setting, while it is mainly an institution-based service in Germany. In its current form, the taxonomy does not pay attention to these subtleties. The experts rated the applicability of the taxonomy in different healthcare systems higher than the accuracy of certain features of the tool.
Consequently, some IPC initiatives in Europe may be only roughly described by the taxonomy.

In its current form, the taxonomy will be especially helpful in comparing IPC initiatives. It provides a conceptual base to discuss and learn about IPC, as well as to identify differences and communalities and compare outcomes. It also gives direction to new initiatives and for further development of existing IPC initiatives. However, although the taxonomy describes important characteristics of IPC, it does not identify an explicit cut-off point between IPC and non-IPC practices. This requires more consensus, which may be easier to achieve on a national or even a regional scale. The taxonomy does provide important ingredients to structure this debate.

Future practical experiences with IPC may help to clarify multidimensional requirements of integrated care concepts. Against this backdrop, certain categories of the taxonomy may be refined or adapted to healthcare systems' particularities. First, practical tests with the taxonomy in the InSuP-C consortium raised the discussion whether outpatient clinics are an essential feature of IPC initiatives, as a supplement in the category sector. Likewise, informal caregivers were discussed as an addition to the taxonomy. Revision of the taxonomy might be required if these or other features turn out to be an important part of IPC initiatives in Europe.

\section{STRENGTHS AND LIMITATIONS}

The taxonomy, emanating from a theoretical discourse, has to be tested in practice to evaluate how it covers the reality of patients in need of palliative care. Thus, it has to be further improved by implementing practical findings of the testing procedure and future 
research. The taxonomy also needs to be part of education activities for all professions concerned in IPC. Although the focus group included multidisciplinary participants, the results may have been influenced by the predominance of physicians and the restriction on European countries. This bias should have been mitigated by the input from 34 expert interviews and online survey among members of the EAPC mailing list contributing broad expertise from other countries and disciplines. While the focus group proved to be a very effective method to conceptualise a taxonomy of IPC initiatives from scratch, limitations of this consensus method include the low number of participants involved in this intense process. In order to overcome this pitfall, the next step in the development of this taxonomy should seek confirmation of the taxonomy after pilot testing with a more formalised procedure such as the Delphi technique.

\section{CONCLUSION}

Since the controversy about IPC frameworks (foremost about the LCP) is 'very emotive', ${ }^{15}$ joint efforts of explaining and communicating IPC to the wider public have to be improved significantly. In this vein, the taxonomy may serve as a useful tool. It will be pilot tested in the 23 IPC initiatives in Belgium, Germany, Hungary, the UK and the Netherlands as part of subsequent work packages of the InSuP-C project. ${ }^{10}$ In addition, it may also be used as

- A template to classify the variety of schemes and initiatives in other areas of care ${ }^{12}$;

- A toolkit for policymakers and professional caregivers to enhance their knowledge on IPC;

- A facilitator for future development and cooperation of IPC.

A refinement of the taxonomy-based on practical experience-is intended.

Acknowledgements InSup-C, Patient-centred integrated palliative care pathways in advanced cancer and chronic disease, is funded by the European Union Seventh Framework Programme (FP7/HEALTH, under grant agreement 305555). InSup-C aims to identify the prerequisites for best practice in integrated palliative care with the overall objective of improving service delivery and service user outcomes. InSup-C is coordinated by Dr Jeroen Hasselaar of Radboud University Medical Center, Nijmegen, The Netherlands. Other partners are: University Hospital, Bonn, Germany; International Observatory on End-of-Life Care, Lancaster University, Lancaster and Sheffield University, UK; University of Pecs Medical School, Pécs, Hungary; University Hospital Leuven, Leuven, Belgium; World Health Organization, Geneva, Switzerland; European Association for Palliative Care (EAPC OnLus), Milan, Italy; Erasmus University, Rotterdam, The Netherlands; University of Navarra, Navarra, Spain; Mount Sinai Medical Center, New York, USA.

Contributors BE, FH and LR organised the focus group. FH developed the preliminary taxonomy. BE drafted and revised the manuscript. FH, LR, JvW, JM, MG and SP critically commented on and amended the manuscript. All the authors (BE, FH, JvW, SP, MG, JH, JM and LR) took part in the project's internal discussions leading to the taxonomy, and read and approved the final manuscript.
Funding The research leading to these results has received funding from the European Union's Seventh Framework Programme (FP7/2007-2013) under grant agreement $\mathrm{n}^{\circ}$ 335555 .

\section{Competing interests None}

Provenance and peer review Not commissioned; externally peer reviewed.

Open Access This is an Open Access article distributed in accordance with the Creative Commons Attribution Non Commercial (CC BY-NC 4.0) license, which permits others to distribute, remix, adapt, build upon this work noncommercially, and license their derivative works on different terms, provided the original work is properly cited and the use is non-commercial. See: http://creativecommons.org/licenses/by$\mathrm{nc} / 4.0 /$

\section{REFERENCES}

1 Partdrige AH, Seah DS, King T, et al. Developing a service model that integrates palliative care throughout cancer care: the time is now. J Clin Oncol 2014;32:3330-6.

2 Goodwin N, Dixon A, Anderson G, et al. Providing Integrated Care for Older People with Complex Needs. Lessons from Seven International Case Studies. http://www.kingsfund.org.uk/ sites/files/kf/field/field_publication_file/providing-integratedcare-for-older-people-with-complex-needs-kingsfund-jan14.pdf (accessed 12 Nov 2014).

3 Singer SJ, Burgers J, Friedberg M, et al. Defining and measuring integrated patient care: promoting the next frontier in health care delivery. Med Care Res Rev 2011;68:112-27.

4 Riley J. Comment: a vision for integrated palliative care pathways. Eur J Palliat Care 2012;2:57.

5 Taylor DH Jr, Bull J, Zhong X, et al. The effect of palliative care on patient functioning. J Palliat Med 2013;16:1227-31.

6 El-Jawahri A, Greer JA, Temel JS. Does palliative care improve outcomes for patients with incurable illness? A review of the evidence. J Support Oncol 2011;9:87-94.

7 WHO. Strengthening of Palliative Care as a Component of Comprehensive Care Throughout the Life Course. WHA67.19, http://apps.who.int/gb/ebwha/pdf_files/WHA67/A67_R19-en. pdf?ua $=1$ (accessed 20 Nov 2015).

8 Chan R, Webster J. End-of-life care pathways for improving outcomes in caring for the dying. Cochrane Database Syst Rev 2013;11:CD008006.

9 Kodner D. All together now a conceptual exploration of integrated care. Healthc Q 2009;13:6-15.

10 van der Eerden M, Csikos A, Busa B, et al. Experiences of patients, family and professional caregivers with Integrated Palliative Care in Europe: protocol for an international, multicenter, prospective, mixed method study. BMC Palliative Care 2014;13:52.

11 InSuP-C Integrated Palliative Care An EU Framework 7 Programme. http://www.insup-c.eu (accessed 6 Nov 2014).

12 Macadam M. Frameworks of integrated care for the elderly: a systematic review. Ottawa: Canadian Policy Research Networks (CPRN), 2008.

13 Hauser JM, Kramer BJ. Family caregivers in palliative care. Clin Geriatr Med 2004;20:671-88, vi.

14 Murray SA, Firth A, Schneider N, et al. Promoting palliative care in the community: producing a toolkit to improve and develop primary palliative care in different countries internationally. EAPC Press: EAPC, 2014.

15 Davis C, Guyer C. Integrated care pathways for dying patients - myths, misunderstandings and realities in clinical practice. $J$ Palliat Care 2013;3:112-19. 